10,0 ц/га соответственно, с преимуществом нулевой технологии в $35 \%$. Урожайные данные 2015 года также были в пользу нулевой технологии $-28,0$ и 25,0 ц/га, с прибавкой в $12 \%$. В среднем за три года урожайность зерна при нулевой технологии была на 2.3 ц/га, или на 14 \% выше, чем при традиционной технологии. Основным фактором, повышающим урожайность при нулевой обработке, выступает почвенная влага. При нулевой технологии в метровом слое почвы содержалось влаги значительно выше, чем при традиционной технологии, на что было указано выше.

\title{
Заключение
}

1 Нулевая технология, состоящая из химической борьбы с сорняками в чистом пару и по всходам культуры, прямого посева на необработанную почву обеспечивает более высокое содержание продуктивной влаги в почве при одинаковой засоренности с традиционной технологией.

2 Благодаря лучшему накоплению и сохранению влаги в почве, нулевая технология способствует формированию более высокой урожайности зерна по сравнению с традиционной технологией.

$$
* * *
$$

1. Система нулевой обработки почвы или «No-till» технология / agros-tory.com / info-centre / 28.09.2017.

2. Сафин Х.М., Шварц Л.С., Фахрисламов Р.С. Технология No-till в системе сберегающего земледелия: теория и практика внедрения. - Уфа: Мир печати, 2013. - 72 с.

\section{Степанов A.A. \\ Применение гуминовых препаратов для переработки котлованных и строительных грунтов в плодородные почвосмеси}

\author{
МГУ им. М.В.Ломоносова \\ (Россия, Москва)
}

doi: $10.18411 / l j-28-02-2018-72$

idsp: 000001:lj-28-02-2018-72

Проведение строительных работ в мегаполисе сопровождается извлечением значительного объема котлованных грунтов, в том числе достаточно тяжелого гранулометрического состава (суглинки, глины). Почвосмеси, приготовленные на основе котлованных и строительных грунтов, могут быть с успехом использованы в целях городского озеленения, в частности для создания искусственных почв конструктоземов и посадки на них многолетних насаждений. Использование почвомодификаторов (питательных смесей, оструктуривателей, природных и синтетических полимеров и т.д.) в мировой практике благоустройства и озеленения территорий ряда стран (США, Канада, страны Европейского Союза, Япония) проводится главным образом на почвах и грунтах достаточно легкого гранулометрического состава (2). Оструктуривание суглинков и глин с их последующим обогащением питательными элементами и органическим веществом не носит широкого распространения.

Целью нашей работы было проведение полевых испытаний природных биополимеров (гуминовых кислот) в качестве почвенных модификаторов при создании городских почв и плодородных почвосмесей на основе котлованных и строительных грунтов тяжелого гранулометрического состава.

В ходе работы на территории почвенного стационара факультета почвоведения Московского Государственного Университета в августе 2010 г были заложены четыре серии полевых опытов с различными вариантами формирования насыпных конструкций (буртов) из глины, песка и торфа (Рис.1):

1. Контроль - послойное заложение компонентов (глина, торф, песок) в объемном соотношении 4\1\1. Обработка слоев гуматом не проводилась; 
2. «Слоистый» - послойное заложение компонентов (глина, торф, песок $4 \backslash 1 \backslash 1)$. При заложении бурта слои обрабатывались раствором гумунового препарата «Экстра». Доза внесения гумата составила 0,2 кг на 1т глины;

3. «Саксонская вспашка» - послойное заложение компонентов (глина, торф, песок - 4\1\1) под углом 45o. При заложении бурта слои обрабатывались раствором гумунового препарата «Экстра». Доза внесения гумата составила 0,2 кг на 1т глины;

4. «Смешанный» - при заложении бурта компоненты (глина, торф, песок 4\1\1) смешивались и обрабатывались раствором гумунового препарата «Экстра». Доза внесения гумата составила 0,2 кг на 1т глины.

Важно отметить, что выбор гуминового удобрения «Экстра», производимого ООО НВЦ «Агротехнологии», в качестве испытуемого почвенного модификатора был не случаен.

Ранее в 2008-2009 гг в рамках выполнения программы научных работ по Государственному контракту Департамента науки и промышленной политики города Москвы «Технологии применения природных гуматов для ремедиации городских почв и в целях стимулирования роста растений» на кафедре химии почв факультета почвоведения Московского университета проводились лабораторные, вегетационные и полевые испытания лучших гуминовых препаратов, производимых в РФ, с целью оценки возможности их применения для детоксикации и ремедиации загрязненных городских почв.

Результаты испытаний с различными тест-культурами показали, что применение промышленных гуматов, в оптимальных дозах ( т.е. 50-100 мг/л или 10-100 кг/га), заметно стимулирует прорастание семян, улучшает дыхание и питание растений и уменьшает поступление в растения тяжелых металлов и радионуклидов.

Практика применения гуминовых препаратов в сельском хозяйстве и ремедиационных технологиях у нас в стране и за рубежом свидетельствует, что наиболее сильный эффект гуматов проявляется при неблагоприятных условиях окружающей среды: при недостаточной или избыточной влажности, низких температурах, недостаточной освещенности или при загрязнении тяжелыми металлами, радионуклидами или органическими поллютантами, так как гуматы, блокируя токсиканты в почвах и благодаря физиологически-активному и протекторному действию повышают устойчивость растений к воздействию неблагоприятных факторов среды.

На завершающем этапе испытаний эффективность действия гуматов была экспериментально подтверждена в ходе полевых экспериментов проводимых в 2009 году в Москве на участках примагистрального озеленения и на опытных площадках почвогрунтов с искусственно созданным загрязнением хлорид-ионами, нефтепродуктами и ионами меди.

Гумат «Экстра» по результатам этих испытаний был признан наиболее сбалансированным по составу, свойствам и набору физиологически активных фракций. Крайне важными в условиях масштабного применения на загрязненных городских почвах являются низкая себестоимость препарата и возможность его применения и хранения как жидком состоянии (рабочие растворы с концентрацией до 100 г/л), так и в виде сухого порошка.

Закладка буртов была проведена 1августа 2010 г. В мае 2011 г часть буртов (112) были использованы для приготовления почвосмесей. После тщательного перемешивания компонентов полученную почвосмесь использовали для формирования опытных площадок (0.25 м2) для выращивания газона (райграс пастбищный). Варианты опыта представлены на рисунке . Посев трав был произведен - 15 июня 2011г. Укосы биомассы, соответственно, 15 июля 2011 г.

Эффективность действия гумата «Экстра» как почвенного модификатора оценивалось по нескольким критериям: изменение плодородия, химических свойств и 
гумусного состояния, структурных и гидрофизических свойств, физиологического состояния микробного сообщества полученных почвосмесей.

\section{Создание конструкций}

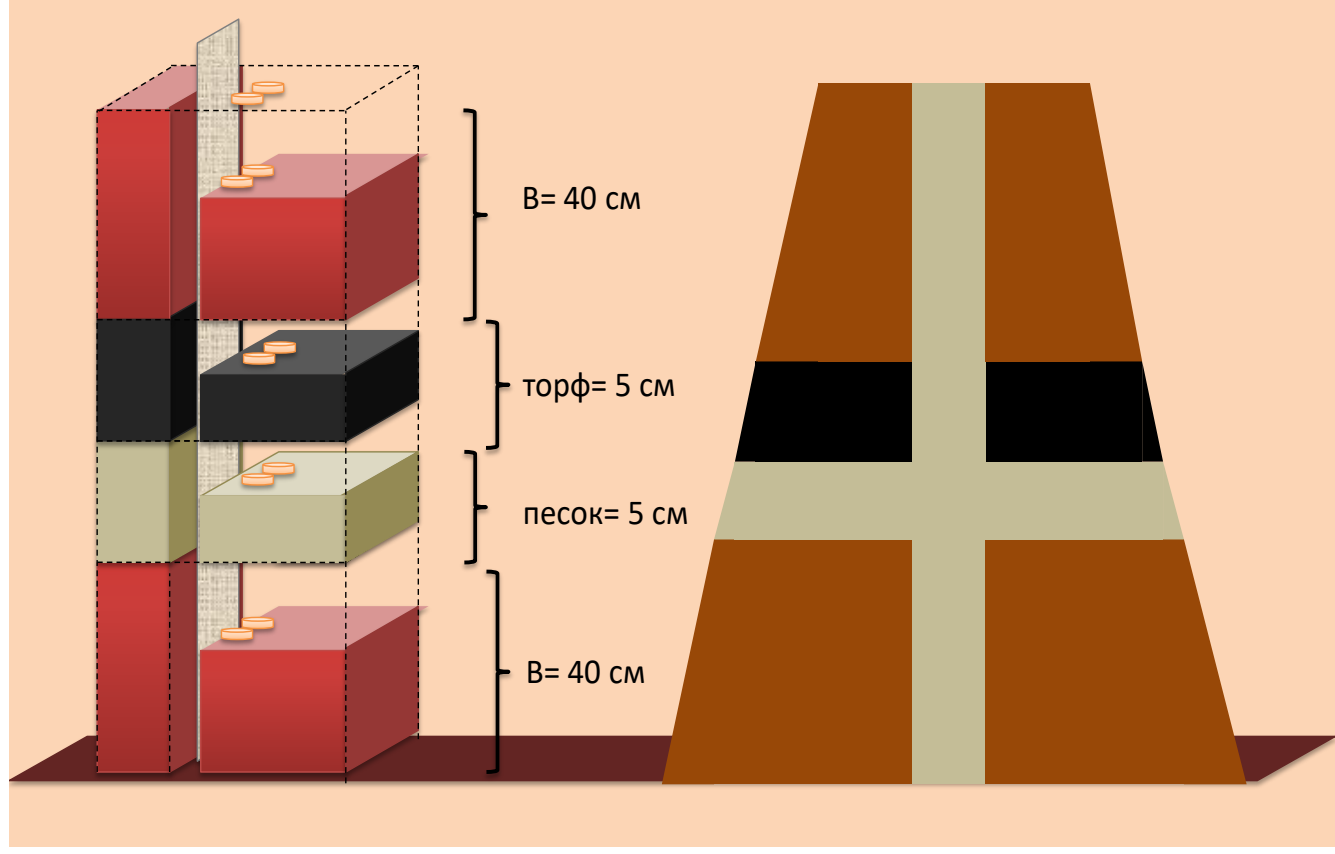

Рисунок 1. Схема заложения конструкций.

Данные учета биомассы газонных трав, выращенных без применения дополнительных мелиорантов, свидетельствуют о том, что в вариантах опыта с внесением гумата биопродуктивность увеличивается не менее чем на 26-30 \% (варианты «слоистый» и «саксонская вспашка»), а в случае вариантом опыта «смешанный» - почти на 50 \%. Результат представляется тем более значимым, если учесть, что количество ГВ, внесенных за 10 месяцев до посева трав, составляло менее $0.1 \%$ от общего содержания ОВ в полученных почвосмесях.

Применение традиционных мелиорантов (торф, минеральные удобрения) и гуматов при выращивании газона позволило увеличить урожайность тест-культуры на опытных площадках в 1,5 - 3,5 раза. Важно отметить, что применение малых доз гумата «Экстра» (5 мл при замачивании 20 г семян и 0.5 мл при обработке всходов) сопоставимо по эффективности с внесением на 1 м 2 газона 4 кг торфа и лишь немногим уступает (на 520 \%) действию комплексного минерального удобрения ( 10 г на м2).

Существенные изменения происходят с составе ОВ полученных почвосмесей. По сравнению с контролем в вариантах с применением гумата возрастает как общее содержание органического углерода ( до 20 \% в случае варианта «слоистый»), так и доля доля гуминовых кислот в составе ОВ (отношение СГК/СФК увеличивается с 0.6 до 0.80.9). Здесь важно отметить, что все химические анализы (в том числе и определение показателей гумусного состояния почвосмесей) проводились в сентябре-октябре 2011года после разбора опытных площадок. Поэтому все отмеченные изменения между вариантами опытов следует считать результатом не прямого, а опосредованного влияния гуминового препарата. Т.е. через создание оптимальных условий для роста и развития почвенной биоты и корневой системы газонных трав. А, следовательно, и увеличения в почве общего количества метаболитов, продуцируемых микроорганизмами и энзимов (корневых выделений) растений. Это, в свою очередь, ускоряет и усиливает процессы 
формирования так называемого «молодого гумуса», т.е. прогуминовых и гуминовых соединений.

Таблица 1

Химические свойства почвосмесей.

\begin{tabular}{|c|c|c|c|c|}
\hline \multirow{2}{*}{ Показатель } & \multicolumn{4}{|c|}{ Вариант опыта } \\
\cline { 2 - 5 } & 1 & 2 & 3 & 4 \\
\hline & & & & \\
$\mathrm{pH}_{\text {вод }}$ & & & & \\
$\mathrm{pH}_{\text {кС }}$ & 5.1 & 6.0 & 5.9 & 6.0 \\
$\mathrm{C}_{\text {орг }}, \%$ & 5.3 & 5.3 & 5.3 \\
гумус, \% & 3.22 & 3.26 & 3.26 & 3.30 \\
$\mathrm{~N}_{\text {общ }}, \%$ & 5.55 & 5.62 & 5.62 & 5.69 \\
мг $\mathrm{K}_{2} \mathrm{O} / 100$ г почвы & 0.05 & 0.09 & 0.06 & 0.13 \\
мг $\mathrm{P}_{2} \mathrm{O} 5 / 100$ г почвы & 10.3 & 13.2 & 10.7 & 12.3 \\
& 10.8 & 12.1 & 9.3 & 12.6 \\
& & & & \\
& & & & \\
\hline
\end{tabular}

Можно предположить, что отмеченное ранее увеличение уровня степени гумификации в вариантах с применением гумата «Экстра» происходит за счет фракций ГК с молекулярным весом в диапазоне 17-25 тыс. а.е.м , о чем свидетельствует результаты определения молекулярных масс исследуемых ГВ методом гель-фильтрации на сефадексе G-75 (Рис. 2).

Как показал опыт исследований последних десятилетий $(1,4)$, гораздо более динамичной характеристикой ОВ почв (по сравнению с такими традиционными показателями гумусного состояния как, например, групповой и фракционный состав гумуса, содержание «свободных» и «прочносвязанных ГК» и другими) является показатель hph, т.е. степень гидрофильности ГВ, отражающий соотношение гидрофобных и гидрофильных компонентов в составе гумуса $(5,6)$.
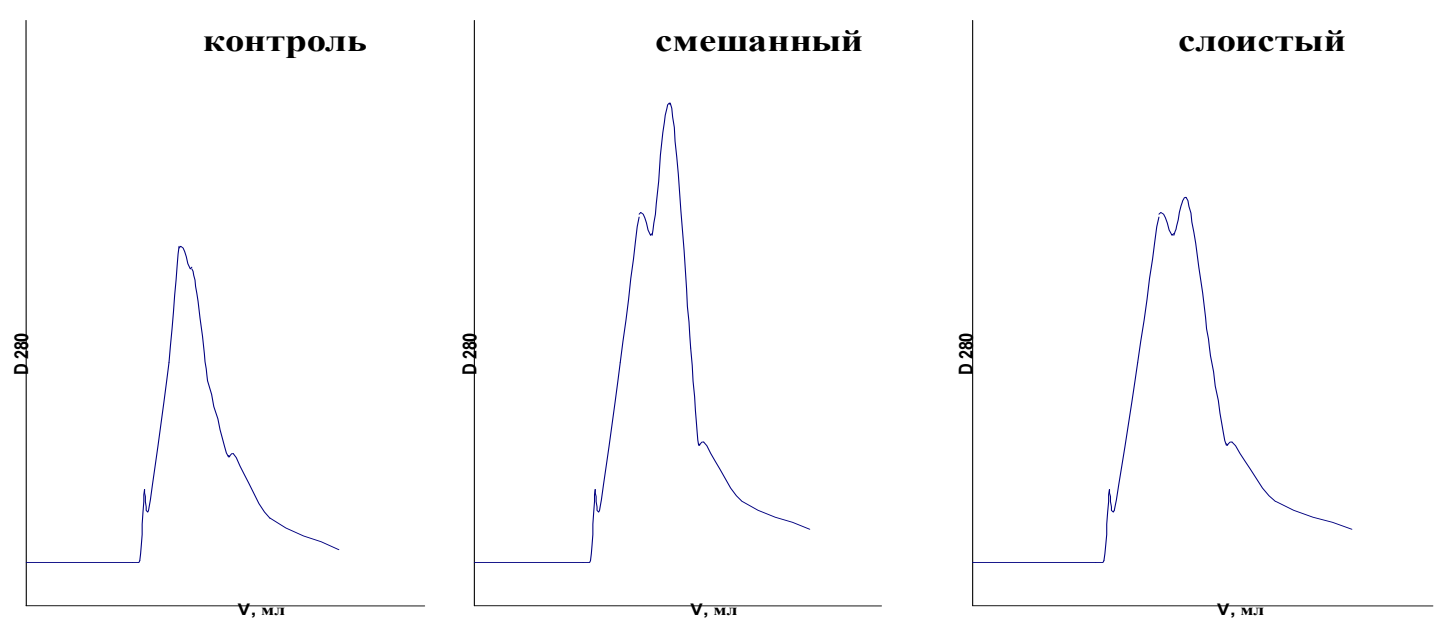

Рисунок 2. Молекулярно-массовое распределение ГВ. 
Изменение показателя связано не с достаточно длительными процессами формирования «зрелых» ГК или образованием металл-органических комплексов, лабильных или прочносвязанных соединений с полуторными окислами, а с изменением поверхностных характеристик молекул ГК и ФК и их ассоциатов. Т.е., в первую очередь, с изменением конфигурации частиц ГВ и распределением заряда на их поверхности. А это часто обусловлено изменением почвенных условий (водный режим, режим аэрации, состав почвенного раствора и прочее). В связи с этим крайне интересным представляются результаты фракционирования ГВ, выделенных из почвосмесей различных вариантов полевого опыта, на гидрофобизованном геле агарозы (Octil-Sepharosa CL-4B, Pharmacia). На хроматограммах хорошо заметно появление дополнительных гидрофильных и гидрофобных фракций в составе ГВ в варианте «смешанный образец» по сравнению с ГВ из контрольного образца. Доля лабильных, потенциально наиболее реакционоспособных ГВ в составе гумуса возросла почти на треть. Соответственно, увеличилось и значение показателя hph с 0,7 до 1,0 .

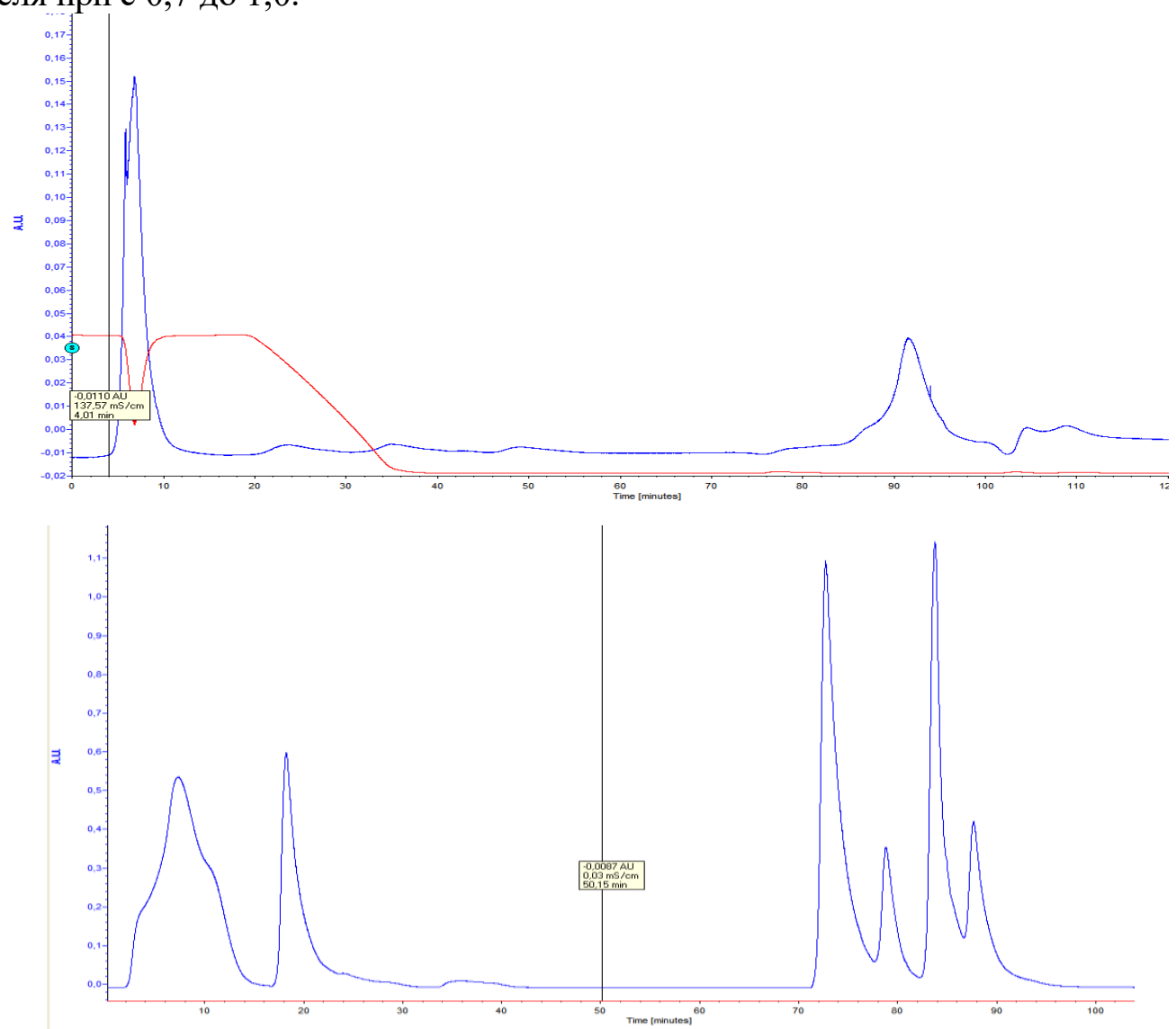

Рисунок 3. Изменение состава амфифильных фракций ОВ.

$$
* * *
$$

1. Милановский Е.Ю. Амфифильные компоненты гумусовых веществ почв // Почвоведение. 2000. №6. С.706-715

2. Орлов Д.С. Гумусовые кислоты почв и общая теория гумификации. М.: МГУ, 1990. 325 с.

3. Пономарёва В.В., Плотникова Т.А. Гумус и почвообразование. М.:Наука, 1980. 223 с.

4. Степанов А.А. Получение амфифильных фракций гуминовых кислот из чернозёма южного и их характеристика// Почвоведение. 2005. №8 С.955-959.

5. Степанов А.А. «Дробное осаждение» как метод получения амфифильных фракций гумусовых кислот// Современные проблемы почвоведения и экологии: тезисы Докл. Школы-семинара молодых ученых. Москва, 1994. С.62.

6. Степанов А.А. Амфифильные фракции гуминовых веществ из препарата «Флексом» как стимуляторы роста растений// Сборник трудов V Всероссийской конференции «Гуминовые вещества в биосфере». Санкт-Петербург, 2010. С.451-454. 